\title{
Enrique Soto Durán
}

\author{
Gracias, Enrique
}

El Consejo Directivo de la Sociedad Uruguaya de Cardiología nos ha encomendado escribir estas líneas como sentido homenaje al Dr. Enrique Soto Durán.

No es difícil encarar esta tarea, cuando la vida de Enrique ha sido ejemplo de permanente compromiso humanista y actitud de servicio.

Médico clínico por excelencia, ejerció la cardiología con un profundo respeto por sus pacientes, a quienes les brindó su tiempo y energía con gran generosidad.

Junto a su dedicación clínica, demostró un fuerte compromiso social, teniendo activa participación en la actividad científico-gremial, que asumió en el Sindicato Médico del Uruguay, así como en la Sociedad Uruguaya de Cardiología, donde alcanzó la presidencia en el año 2017.

Asumió responsabilidades políticas en la Dirección del Fondo Nacional de Recursos (FNR), así como en la Administración de los Servicios de Salud del Estado (ASSE).

Finalmente, a partir del año 2012, ejerció la Dirección del Departamento de Cardiología en CASMU-IAMPP, donde logró cohesionar con dedicación y solvencia a un gran grupo de colegas, integrándolos en actividades científicas de educación médica, ateneos, distribución generosa de bibliografía, así como en el desarrollo de nuevos servicios y planes tera-

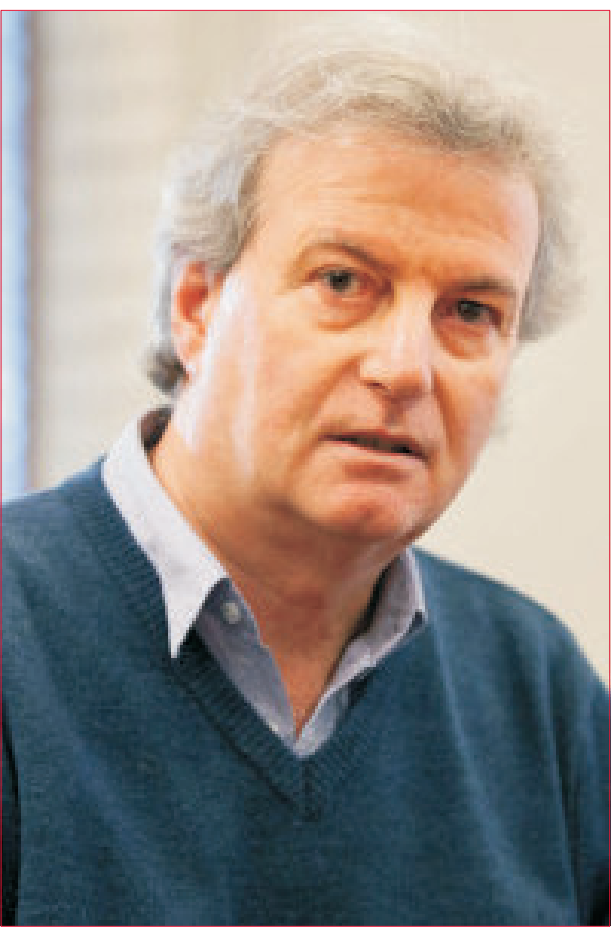
péuticos, que configuraron un crecimiento para todos los que pudimos colaborar con su gestión.

Esta intensa labor profesional estuvo siempre acompañada por una hermosa familia que fue su sostén afectivo: Julia, su esposa, sus tres hijos y siete nietos al momento de su partida.

Gracias, Enrique, por tu actitud. Tu familia y tus pacientes te extrañarán, tus amigos, recordándote, continuaremos en la misma ruta de servicio y compromiso humanista.

\section{Dr. Daniel Barreiro. Departamento de Cardiología del Centro de Asistencia del Sindicato Médico del Uruguay, CASMU-IAMPP.}

\section{Enrique Soto: estetoscopio y militancia}

La comprensión de los procesos salud/enfermedad (las cardiopatías no podrían ser una excepción) supone conocer e integrar dimensiones biológicas, psicológicas y sociales. Su gestión es un asunto político y la toma de decisiones, se sea o no consciente de ello, está atravesada de ideología.

Esto fue lo primero que me vino a la mente cuando la Revista Uruguaya de Cardiología me pidió una reflexión sobre Enrique Soto Durán y su compromiso social y político.

Fue un médico de muchas horas de consultorio por día. Era el cardiólogo de muchísimas personas que lo recuerdan bien, ante todo, por su trato, seguramente a partir del arte de la escucha, la mirada y el manejo del tiempo en la consulta.

Pero también dedicó otras tantas horas del día y la noche a la militancia social y política.

Su vocación médica, gremial y política se manifestó en la Sociedad Uruguaya de Cardiología, que le tocó presidir; en el Sindicato Médico del Uruguay, del que fue vicepresidente y, más recientemente, en el Colegio Médico del Uruguay, cuyo Consejo Nacional lo tuvo como secretario (me consta, tenía la convicción de que 
había que perfeccionar la Ley № 18.591 que lo creó). En su actividad política militaba en el Frente Amplio, en la Vertiente Artiguista, que ayudó a fundar, grupo por el que fue senador suplente.

Esa mixtura de médico y ciudadano comprometido lo llevó a ocupar diversas responsabilidades en lugares de diseño o gestión de políticas sanitarias, sea como vicepresidente de ASSE, presidente del FNR o como director del Programa del Control de Tabaco del Ministerio de Salud Pública.

Dejó la consulta solo cuando se enfermó de COVID-19. Había asistido a 70 pacientes esa semana. En ese momento colgó el estetoscopio, pero no apagó el celular. Me hizo creer en una mejoría cuando el 6 de diciembre hizo llegar su mensaje de dolor por la muerte del expresidente Tabaré Vázquez. Pero no, seguía en CTI, grave, y moriría nueve días después.

Fue entonces cuando su familia y allegados más cercanos hicieron público su deseo de que no se le enviaran flores y el dinero se volcara a la olla popular del club Huracán del barrio Paso de la Arena.

A quienes somos parte de una profesión a veces señalada como abducida por el interés del lucro y la mercantilización de la salud, la vida y la muerte de Enrique Soto nos dicen unas cuantas cosas.

\section{Dr. Hugo Rodríguez. Departamento de Medicina Legal, Facultad de Medicina, Universidad de la República.}

El Dr. Enrique Soto se desempeñó como presidente alterno de la Comisión Honoraria Administradora del Fondo Nacional de Recursos (FNR) desde abril de 2010 hasta octubre de 2011.

Durante su presidencia muchas fueron las resoluciones adoptadas de las que mencionaremos solo algunas:

- Se incorporaron nuevos medicamentos a la cobertura financiera del FNR como el bortezomib para el mieloma múltiple, nilotinib para el tratamiento de las leucemias y GIST, bosentan e iloprost para el tratamiento de la hipertensión arterial pulmonar, anti-TNF para el tratamiento de la enfermedad de Crohn y fibrinolíticos para el tratamiento del infarto agudo de miocardio en el marco de un programa nacional.

- Se aprobó la firma del convenio marco para el establecimiento del programa de salud renal en los Servicios de Salud de ASSE, con apoyo del FNR.

- Se aprobó la implementación de un sistema de comunicación electrónica entre el FNR y los IMAE lo que resultó en el puntapié inicial para lo que es hoy un sistema totalmente informatizado.

- Se acreditaron ante la Escuela de Graduados los cursos de Capacitación en Tratamiento del Tabaquismo y de Prevención y Control de las Infecciones Intrahospitalarias.

- Se resolvió la realización de un convenio con el Centro Uruguayo de Imagenología Molecular, para la prestación de servicios de tomografía por emisión de positrones (PET-SCAN).

- Se dispuso la adhesión institucional del FNR a la Red de Actividad Física de Uruguay (RAFU).

- Se decidió enviar una representación del FNR ante la Comisión Asesora de Enfermedades Crónicas no Transmisibles designando al Presidente Dr. Enrique Soto y a la Subdirectora Técnico-Médica, Dra. Rosana Gambogi.

- Se resolvió aprobar la ampliación del programa del tratamiento del tabaquismo y la implementación de un programa piloto de tratamiento de la obesidad.

- Se realizó una encuesta de opinión realizada por la empresa Factum, que fue publicada, y se celebró el 30 aniversario del FNR con diversas actividades.

- Se realizaron instancias con los distintos servicios del FNR, con el fin de instrumentar un cuestionario a los funcionarios para evaluar la dinámica interna de la organización del FNR, en el marco del Sistema Matricial de Control Interno, realizándose jornadas con los funcionarios del Fondo, a fin de lograr mayor eficiencia, bienestar y compromiso en las distintas áreas.

Más allá de resoluciones puntuales, el accionar de Enrique Soto en la presidencia del FNR contribuyó a la reflexión sobre la organización, fortaleciéndolay preparándola para los avatares que se presentaron en el futuro.

Toda su gestión estuvo signada por la combinación de la mayor responsabilidad en el cuidado de los bienes públicos y el absoluto respeto a la profesión médica de la cual fue acérrimo defensor, firme en sus ideas y respetuoso en el disentimiento.

Fondo Nacional de Recursos 